\title{
Ciência e educação na década de 1950: uma reflexão com a metáfora percurso*
}

\author{
Marcus Vinicius da Cunha \\ Universidade de São Paulo, Faculdade de Filosofia, Ciências e Letras de Ribeirão Preto
}

\section{Introdução}

A década de 1950 representou grande avanço na pesquisa científica relacionada à área de educação no Brasil, fato que se deve, em grande parte, à instituição do Centro Brasileiro de Pesquisas Educacionais (CBPE) e de seus congêneres Centros Regionais, instalados em São Paulo, Recife, Salvador, Belo Horizonte e Porto Alegre. Criado em 1955, o CBPE era subordinado ao Instituto Nacional de Estudos Pedagógicos (INEP), órgão do Ministério da Educação e Cultura. Desde 1952, o INEP foi dirigido por Anísio Teixeira, que foi também o primeiro diretor do CBPE.

Sem desconsiderar os projetos e as atividades de pesquisa efetivamente desenvolvidas pelo CBPE e pelos Centros Regionais, bem como a sua inserção

\footnotetext{
* Este trabalho resulta de pesquisa subsidiada pelo CNPq.
} Trata-se de uma versão ampliada, e com outro subtítulo, da comunicação apresentada pelo autor no $25^{\circ}$ International Standing Conference for History of Education (ISCHE), realizado em São Paulo, em julho de 2003. no âmbito da política e da administração pública, ${ }^{1} \mathrm{o}$ presente trabalho visa a situar a relevância de tais iniciativas governamentais para o surgimento de um debate quanto ao sentido da pesquisa científica no campo da educação. Trata-se de mostrar que a criação do CBPE permitiu aflorar significativa discussão quanto ao conceito de pesquisa educacional e à definição do papel da ciência - especialmente no caso das ciências sociais - na investigação dos problemas da escola brasileira e na busca de suas soluções.

O tema é inspirado em Libânia Xavier (1999) que, ao analisar o CBPE, destaca dois posicionamentos relativos aos vínculos possíveis entre ciência e educação, representados pelas figuras de Anísio Teixeira e Florestan Fernandes. As elaborações teóricas de Teixeira sobre o tema datam dos primórdios do movimento escolanovista, uma vez que no ideário da Escola Nova sempre constou marcada ênfase na necessidade de modernizar as práticas pedagógicas me-

${ }^{1}$ Ver Cunha (1991), Brandão e Mendonça (1997), Xavier (1999) e Ferreira (2001). 
diante a incorporação de conhecimentos e métodos oriundos da esfera científica. Dada a urgência assumida pelos problemas da educação no pós-guerra, e considerando a noção de planejamento elaborada e difundida internacionalmente pela Organização das Nações Unidas para a Educação, a Ciência e a Cultura (UNESCO), são emblemáticas as palavras de Teixeira (1952, p. 79) ao assumir a direção do Instituto Nacional de Estudos e Pesquisas Educacionais (INEP): sua intenção era incentivar investigações científicas sobre a realidade educacional brasileira, lançando assim as "bases de nossa ciência da educação". Os centros de pesquisas significavam um passo decisivo no processo de renovação educacional desencadeado nos anos de 1930. Para renovar a educação, era preciso, antes de tudo, olhar os fatos escolares por intermédio da ciência, o que possibilitaria planejar racionalmente as ações político-administrativas voltadas à superação dos entraves nessa área.

A intervenção de Florestan Fernandes deu-se por ocasião do Simpósio sobre Problemas Educacionais Brasileiros, promovido em 1959 pelo Centro Regional de Pesquisas Educacionais de São Paulo. No evento, Fernandes apresentou o texto A ciência aplicada e a educação como fatores de mudança cultural provocada, ${ }^{2}$ o qual, segundo Xavier (1999, p. 188), evidenciou "a visão de um sociólogo da USP sobre os riscos de desvirtuação do projeto de associar educadores e cientistas sociais", indicando "os limites e possibilidades da ação integrada" entre esses profissionais "no planejamento racional das políticas educacionais" (idem, p. 192).

A autora considera o Centro Brasileiro e os Centros Regionais - e, por extensão, o simpósio paulista iniciativas que possibilitaram o desenho de um "campo de consensos e de contradições" que possibilita delimitar a "contribuição da geração dos pioneiros da

${ }^{2}$ Publicado primeiramente em Ensaios de sociologia geral e aplicada (Fernandes, 1966). Analisarei aqui a publicação de Estudos e Documentos, da Faculdade de Educação da USP, que dedicou duas edições ao referido simpósio. educação nova" e "a sua superação pela nova geração de cientistas sociais representada por Darcy Ribeiro, no Rio de Janeiro, e por Florestan Fernandes, em São Paulo" (idem, p. 262).

Seguindo essas indicações, tomaremos Anísio Teixeira e Florestan Fernandes como representantes de duas concepções quanto aos vínculos da pesquisa científica com a educação, as quais, se não eram propriamente opostas, pelo menos revelam a existência de duas vertentes de pensamento. Para analisá-las, tomaremos a sugestão de Tarso Mazzotti (2002): a análise retórica, especialmente a metáfora percurso.

\section{A metáfora percurso}

Metáfora é o recurso da língua que consiste em atribuir predicados a algo que não se conhece, com base em algo já conhecido. Trata-se de uma condensação de qualidades atribuídas a algum objeto, produzida por meio de analogia ou mediante o processo de "acomodar algo novo em esquemas ou estruturas cognitivas anteriores" (Mazzotti \& Oliveira, 2000, p. 14). Na expressão "jardim-de-infância" cunhada por Froebel, por exemplo, podemos ver a metáfora da semeadura, pela qual a criança, o ser humano e a educação assumem representações que se identificam com a atividade de cultivo. A utilidade dessa metáfora, bem como de outras no campo da educação, é que ela serve à definição de objetivos e ao desencadeamento de ações pedagógicas (idem, p. 33).

Analisar as metáforas contidas nos discursos educacionais é uma maneira de desvendar os valores e os meios pelos quais são formalizadas as proposições que se destinam a preservar ou alterar práticas pedagógicas vigentes, o que, conseqüentemente, permite a crítica de suas intenções. Na análise das metáforas, o que está em causa não é propriamente o quanto de verdade cada uma delas carrega, mas sim a sua efetividade perante o auditório em que são pronunciadas. Sendo um instrumento do discurso retórico, uma metáfora será efetiva na medida em que os ouvintes possuírem disposições favoráveis a ela. É assim porque, como diz Aristóteles (2000, p. 3), já que 
os argumentos retóricos destinam-se a julgamentos, impõe-se que o orador coloque a si mesmo em determinada disposição perante seus juízes, ao mesmo tempo em que deve colocá-los em disposições que lhe sejam favoráveis.

A metáfora percurso é uma noção-chave das teorias pedagógicas, uma vez que todas as proposições dessa área referem-se a maneiras de levar o educando de um estado de menor educação para outro, considerado superior ao primeiro por ser provido de mais educação (Mazzotti, 2002, p. 128). Daí o universo vocabular dos educadores incorporar palavras que designam alterações de estado, como currículo, curso, desenvolvimento e processo, entre outras. Cada uma dessas palavras tem conotações particulares nas teorias que as originam, mas podem ser igualmente subsumidas à metáfora percurso.

Percurso, por sua vez, possui dois sentidos "concorrentes e antagônicos" (idem, p. 127): o percurso "determinado e determinável", passível de ser previamente estabelecido e submetido a controles à medida que se realiza, e o percurso que não se submete a planejamento, justamente por ser imprevisível, incerto, que só se dá a conhecer no momento mesmo em que acontece. Nessa última acepção, "A contingência rege o percurso que se faz em seu desenrolar" (idem, p. 128).

A metáfora percurso pode vir associada à metáfora organismo ou à metáfora piquenique (idem, p. 129), sendo que a primeira se identifica com a metáfora percurso determinado, pela qual os predicados atribuídos à educação conduzem à idéia de estrutura organizada, organismo vivo em que as partes se coordenam sob o comando de determinados condicionantes - no caso da educação, instituições ou saberes especializados. A metáfora piquenique, por sua vez, integra a metáfora percurso indeterminado, representando uma dinâmica guiada pela liberdade dos agentes pedagógicos, submetidos apenas às contingências do processo. ${ }^{3}$

${ }^{3}$ Mazzotti associa a metáfora organismo a Platão e a metáfora piquenique (tradução de Bárbara Cassin para homonóia consenso social) a Aristóteles.
Procuraremos mostrar a seguir que os posicionamentos de Anísio Teixeira, juntamente com outros educadores brasileiros vinculados ao CBPE e inspirados nas idéias de John Dewey, podem ser descritos pela metáfora percurso indeterminado, ao passo que as idéias apresentadas por Florestan Fernandes, ao lado de outros participantes do Simpósio de 1959, podem ser posicionadas em torno da metáfora percurso determinado. A distinção entre eles está no modo como enxergam as relações entre a ciência e a educação.

\section{Anísio Teixeira e a educação como arte}

Em seu discurso de posse no INEP, Teixeira (1952, p. 79) é bastante cauteloso ao expressar suas convicções quanto ao estabelecimento das "bases de nossa ciência da educação". Aplicaremos, diz ele, "métodos objetivos e, quando possível, experimentais, mas tudo conduziremos com o sentimento profundo do caráter provisório do conhecimento", pois a ciência não fornece "receitas para as soluções dos nossos problemas, mas o itinerário de um caminho penoso e difícil, com idas e voltas, ensaios e revisões, em constante reconstrução".

A palavra itinerário explicita a filiação do discurso de Teixeira à metáfora percurso; mais precisamente à metáfora percurso indeterminado, pois não descreve o caminho oferecido pela ciência como pleno de certezas e estratégias infalíveis, linear e previamente determinável. Ao contrário, vê as alternativas da ciência dentro de um universo instável, no qual o conhecimento é provisório. No pensamento de Anísio Teixeira, predomina uma sensível consideração pelo elemento humano, o que o leva a atribuir um caráter de imprevisibilidade à educação e, conseqüentemente, a ver como limitadas as possibilidades de a ciência atuar como tutora dos assuntos pedagógicos.

Em carta de 1940 a Fernando de Azevedo, Teixeira admite que, "Se houver uma ciência da educação", isto aumentará nosso "poder de modificar a educação", uma vez que a descoberta das "leis fundamentais" do mundo capacita o homem a transformar o próprio mundo. Adiciona, porém: "Mas a transforma- 
ção, o sentido da transformação obedeceu ao arbítrio humano. Ora, a educação é sobretudo um sentido. E este sentido é arbitrário ou imposto pelas instituições?" (apud Vidal, 2000, p. 42-43, grifos do original).

A palavra sentido integra Teixeira mais uma vez à metáfora percurso. E, igualmente, à metáfora percurso indeterminado, o que se conclui pela menção às contingências impostas pelo arbítrio humano. $\mathrm{Na}$ mesma carta, ele diz ainda: "a educação é, sobretudo, uma arte que progride como progride a música". Esse posicionamento o impede de compartilhar o ponto de vista de Azevedo quanto à sociologia educacional, ${ }^{4}$ pois embora concorde que "o filósofo da educação precisa de trabalhar cada vez mais sobre os dados da ciência”, não crê que exista uma ciência da educação, mas apenas "uma ciência do fenômeno social e uma ciência do fenômeno psíquico e uma, talvez, do psicossocial" (idem, p. 43).

Se aderisse à idéia de uma ciência da educação uma sociologia da educação, como preconizava Azevedo -, Anísio Teixeira assumiria a metáfora percurso determinado, uma vez que admitiria ser a educação passível de norteamento. Ao contrário disso, prefere a metáfora arte para descrever a educação. Arte, para ele, não se opõe radicalmente a ciência, desde que esta não seja vista como conjunto de conhecimentos capazes de definir as finalidades educacionais.

O problema das ciências da educação, vistas como ciências capazes de tutelar a prática pedagógica, está no afastamento entre filosofia e ciência. Anísio Teixeira esclarece esse tema no texto Ciência e arte de educar, quando diz que "pode parecer e parece que ciência e filosofia se opõem e os conhecimentos serão tanto mais científicos quanto menos filosóficos", porém, a realidade é que "filosofia e ciência são dois pólos do conhecimento humano", sendo que entre ambos deve existir um "comércio permanente", no qual "a filosofia nutre permanentemente a ciência e a ciência nutre a filosofia" (Teixeira, 1957, p. 15).

A concepção que separa a filosofia da ciência

${ }^{4} \mathrm{O}$ comentário vem a propósito do livro Sociologia educacional, de Fernando de Azevedo (São Paulo: Melhoramentos, s/d.). deve-se ao preceito de que só à filosofia cabe determinar os fins das atividades humanas, ao passo que à ciência resta cuidar dos aspectos práticos dessas mesmas atividades. Essa visão dicotomizada gera a idéia de uma ciência da educação desprovida de filosofia, em que os conhecimentos filosóficos são tidos como supremos, verdades imutáveis, transcendentais. $\mathrm{Na}$ visão de Anísio Teixeira, porém, a proximidade entre filosofia e ciência torna-se viável porque a primeira é vista como um campo de saberes estreitamente vinculados à realidade do mundo, e o mundo, por sua vez, é percebido em estado de permanente mudança. Essas idéias inviabilizam a elaboração de verdades distanciadas da experiência humana concreta.

Quanto às finalidades educacionais, estas não podem ser definidas nem por uma filosofia, nem por uma ciência, mas devem resultar do íntimo intercâmbio entre ambas: uma filosofia que seja científica, uma ciência que alimente a filosofia - e tal cooperação só pode ser frutífera no terreno mesmo da prática pedagógica. Anísio Teixeira diz, então, que a pesquisa educacional, como a projetada para os centros de pesquisa do INEP, deve realizar justamente essa meta:

O sociólogo, o antropólogo e o psicólogo social não são sociólogos-educacionais, ou antropólogos-educacionais, ou psicólogos-educacionais, mas sociólogos, antropólogos e psicólogos estudando problemas de sua especialidade, embora originários das "práticas educacionais".

Os educadores [...] não são, repitamos, cientistas, mas, artistas, profissionais, práticos [...] exercendo, em métodos e técnicas tão científicas quanto possível, a sua grande arte, o seu grande ministério. (Teixeira, 1957, p. 17)

\section{John Dewey e a teoria quântica ${ }^{5}$}

Na década de 1950, os periódicos do INEP e do CBPE - Revista Brasileira de Estudos Pedagógicos

${ }^{5}$ Especialidade da física que se ocupa de fenômenos e objetos em escala atômica ou subatômica. A palavra quântica vem de Planck, para quem a luz não se propaga em fluxo contínuo, mas na forma de "pacotes" - quanta. 
e Educação e Ciências Sociais, respectivamente - publicaram artigos com posicionamentos semelhantes ao de Anísio Teixeira, particularmente quanto à colocação da idéia de "mundo em movimento" como eixo de suas reflexões. Conforme já analisamos anteriormente (Cunha, 2001), autores como Jayme Abreu, João Roberto Moreira e Newton Sucupira, além do próprio Teixeira, repercutiram a idéia de que não há valores a priori capazes de indicar os princípios da educação, o que se explica pelo estado de permanente alteração a que estão submetidos todos os componentes materiais e imateriais da existência humana.

Tais discussões trazem a marca das influências do pragmatismo de John Dewey no ideário educacional brasileiro e posicionam os conceitos e as práticas do campo pedagógico na esfera da metáfora percurso indeterminado. De fato, Dewey talvez seja o filósofo da educação que melhor incorpora essa metáfora. Em sua obra A busca da certeza, de 1929, ele esclarece que seus pressupostos encontram respaldo nos recentes desenvolvimentos da física, particularmente da mecânica quântica, especialidade que introduziu no pensamento científico, por meio de Heisenberg e outros, o "princípio da indeterminação" (Dewey, 1952, p. 176).

A relevância desse princípio consiste na superação de certos postulados da teoria newtoniana, segundo a qual é possível determinar precisamente a localização e a velocidade de um corpo e, assim, predizer a direção de seu deslocamento posterior. A suposição de Newton baseia-se na existência de partículas imutáveis, eternas, substâncias últimas que interagem entre si sem alterações de qualquer espécie. Para Dewey, essa teoria veio satisfazer a busca de garantias para a existência humana e o conhecimento das coisas naturais pelo homem, traduzindo a crença em um Deus criador de elementos sólidos, indivisíveis e duráveis, inatingíveis pela mudança; enfim, substâncias ou essências - seguindo a tradição da filosofia grega e sua versão medieval - sobre as quais é possível afirmar certezas também fixas e imutáveis (idem, p. 103-104).

O principal equívoco apontado por Dewey (idem, p. 124-125) na formulação newtoniana é que ela su- põe a existência de uma armadura imutável, dentro da qual todos os fenômenos ocorrem. Como representação terrena do ser último das coisas, transmite a idéia de um tempo e um espaço vazios, nos quais as substâncias particulares são invariáveis, tornando-se passíveis de rigoroso e preciso cálculo. $\mathrm{Na}$ física de Newton, todos os fenômenos são matematicamente previsíveis, posto que o universo é formado por pontos geométricos perfeitamente delineados.

A concepção de uma esfera espaço-tempo preexistente gerou o problema central da filosofia moderna, a relação sujeito-objeto (idem, p. 105-106). As qualidades sensíveis dos objetos são vistas como independentes do observador, o que desencadeia a necessidade de determinar as possibilidades e os meios do conhecimento. No livro Reconstrução em filosofia, de 1920, Dewey diz que a discussão filosófica, ao se sustentar "na suposição de um espírito meramente contemplativo, por um lado, e, por outro lado, na hipótese de um objeto estranho e remoto que deve ser contemplado e observado", transforma o ato de conhecer em uma maneira de nos apropriarmos de objetos já existentes, o que aprisiona a filosofia nos "enigmas epistemológicos que atualmente a complicam" (Dewey, 1959, p. 130).

Ao supor a existência de objetos cuja existência antecede o ato mesmo de conhecer, o preceito epistemológico falseia o objetivo da pesquisa científica. Para Dewey, a investigação não deve estar "antecipadamente empenhada em chegar a algum resultado especial", pois se é correto dizer que "todo conhecimento tem um fim além de si mesmo", isto não significa afirmar que "um ato de conhecer tem um fim peculiar, ao qual de antemão se obriga a chegar" (idem, p. 147). Dewey explicita, então, uma de suas teses fundamentais sobre a ciência e os construtos teóricos que a compõem: "noções, teorias, sistemas, por elaborados e autoconscientes que sejam, devem ser encarados apenas como hipóteses, aceitas simplesmente como bases de ação que os comprove, e nunca como algo de último e final" (idem, p. 146).

Em A busca da certeza, Dewey incorpora um significativo avanço às suas reflexões, pois no decorrer 
dos anos de 1920, incrementa-se o debate no campo da física sobre os conceitos científicos advindos de Newton. Na verdade, o desmoronamento do universo newtoniano já vinha ocorrendo desde o início do século XX com as teorias sobre a relatividade restrita de Einstein, de 1905-1906, e a da relatividade geral, de 1916. Dewey (1952, p. 127) concorda que as proposições einsteinianas eliminam a idéia de espaço e tempo como entidades absolutas e independentes e mostram que os enunciados da física designam relações entre eventos e não propriedades intrínsecas de objetos - o que contraria a metafísica newtoniana. ${ }^{6}$

A agitação conceitual na área da física culminou em 1927, com a chamada "interpretação de Copenhague" sobre os postulados da teoria quântica: o que se deduz da observação de um evento atômico só pode ser enunciado em termos probabilísticos, fato que se deve, em parte, ao largo componente de incerteza inerente ao nosso conhecimento sobre os eventos observados - "nosso conhecimento incompleto do mundo" (Heisenberg, 1999, p. 80). Segundo Werner Heisenberg (idem, p. 75), "não podemos objetivar completamente o resultado de uma observação experimental, e não temos como descrever o que 'acontece' entre essa observação e a seguinte". Todos os enunciados da física, portanto, contêm uma demarcação estritamente probabilística.

Ao comentar tais princípios, Dewey (1952, p. 176-177) destaca que a filosofia mecanicista da natureza supõe um esquema fixo integrando passado e futuro, de maneira que, se pudermos determinar precisamente, no tempo e no espaço, as características de um evento já ocorrido, poderemos predizer o seu desdobramento posterior. Os novos desenvolvimentos da física lançam por terra essa pretensão, juntamente com a crença - ou ilusão, como sugere Heisenberg (idem, p. 81) - na possibilidade de descrever o mundo sem fazer "referência alguma a nós

${ }^{6}$ Heisenberg (1999, p. 164-166) explica o clássico experimento de Einstein sobre o conceito de simultaneidade. Dewey (1952, p. 126-127) menciona o assunto em A busca da certeza. mesmos". A teoria quântica postula que "aquilo que observamos não é a Natureza em si mas, sim, a Natureza exposta ao nosso método de questionar" (idem, p. 85). O que é descrito pelo observador não é um evento, simplesmente, mas uma situação complexa que envolve o evento, o observador e o instrumento pelo qual se faz a observação.

Dewey (idem, p. 179) concorda com essa tese, dizendo que os avanços da física trazem à filosofia a oportunidade de superar a velha teoria especular do conhecimento, uma vez que o conhecer passa a ser entendido como um gênero de interação que ocorre no mundo. A filosofia tem a oportunidade de abandonar a tradicional ilusão de tentar encontrar certezas baseadas em verdades eternas e, em troca disso, pode dispor-se a buscar o aprimoramento dos meios de controle ativo das transformações sofridas pelos fenômenos. Ao invés da aplicação de leis supostamente imutáveis, Dewey (idem, p. 181) preconiza a elaboração de fórmulas descritivas de relações entre eventos - fórmulas que, em sentido preditivo, devem ser consideradas como meramente probabilísticas, evidentemente.

Tais reflexões de Dewey, repercutidas por Anísio Teixeira, indicam que as propostas de renovação educacional descrevem uma trajetória incerta. Se vale afirmar que a incorporação das ciências ao campo pedagógico auxilia na superação dos problemas da educação, tornando-a mais adequada aos tempos modernos, é preciso admitir também que não há nenhuma perspectiva de as formulações científicas determinarem um itinerário previamente planejado. $\mathrm{O}$ máximo que se pode conceber, como diz Teixeira, é que a associação de várias áreas científicas auxilie na definição de um percurso em constante reconstrução, nos limites indefinidos de um mundo em permanente mutação.

O universo da educação assemelha-se, sim, ao espaço aberto em que Deus joga dados. ${ }^{7}$ Parafraseando Heisenberg (1999, p. 130) em sua crítica das filo-

\footnotetext{
${ }^{7}$ Refiro-me à expressão de Einstein: "Deus não joga dados",
} em sua polêmica com a interpretação de Copenhague (Heisenberg, 1999, p. 116-117). 
sofias cartesiana e kantiana, é possível dizer que nunca saberemos precisamente "quão longe palavras e conceitos nos ajudarão a achar nosso caminho no entendimento do mundo". Mas isto não significa que a racionalidade presumida pelas ciências não possa auxiliar nesse caminho, desde que aceitemos "que o significado de um conceito jamais será definido com precisão absoluta" e que certos princípios são "instrumentos indispensáveis na execução do trabalho científico em nosso tempo" (idem, p. 131, grifos meus) - provisórios, portanto, passíveis de superação por futuras descobertas, as quais ocorrerão ao longo do próprio caminhar.

É nessa mesma direção que Dewey (1958, p. 13) faz a defesa de sua concepção pragmatista no livro Philosophy of education, publicado anos mais tarde: ${ }^{8}$ a relatividade característica desse movimento filosófico é a mesma que distingue toda investigação científica, pois esta também considera que seus padrões de trabalho são fornecidos pelas "conexões atuais entre as coisas". Quando tais conexões precisam ser generalizadas, impõe-se o respeito à noção de "espaço-tempo", o reconhecimento de que as conclusões científicas são dependentes de determinado tempo e lugar. Assim, fica assegurada a aplicabilidade, "em nosso tempo", dos achados da ciência, desde que reconhecidos como válidos pela comunidade científica atual. Ao mesmo tempo, fica garantido que os dados de agora só têm validade se conectados a outras verificações, feitas em diferentes espaços e em outros tempos.

Essa é a visão do pragmatismo em todos os campos da atividade humana a que se dedica. Não se pode acusá-lo de não aceitar direcionamentos éticos para os problemas atuais da humanidade, pois a concepção pragmatista contempla a existência de princípios válidos, desde que definidos por meio do debate livre e aberto a todos os membros da coletividade. O que não cabe no âmbito da filosofia deweyana é que as

${ }^{8}$ Coletânea de artigos escritos entre 1935 e 1945. O trecho aqui comentado pertence à Introdução, elaborada em 1946 para a primeira edição do livro. definições morais se tornem cristalizadas, como se fossem eternas, motivadas por posições absolutistas.

\section{Florestan Fernandes e o discurso da racionalidade}

No trabalho apresentado durante o simpósio do Centro Regional de Pesquisas de São Paulo, Florestan Fernandes defende a necessidade de fazer convergir os conhecimentos científicos para o terreno da educação, no intuito de tornar a escola um agente de mudança cultural. Contrapondo-se à viabilidade de "mudanças culturais espontâneas", Fernandes (1967, p. 17) enfatiza a transformação pautada no "modelo da ação planificada", no planejamento, este "símbolo organizatório da civilização produzida pela ciência". Para ele, o único conhecimento aplicável a situações práticas é aquele que se desenvolve no âmbito da racionalidade científica, fora da esfera do senso comum, em que imperam valores extracientíficos.

Diferentemente de Anísio Teixeira, as idéias de Fernandes integram-se à metáfora percurso determinado, pois concebem a "mudança cultural provocada" como a transformação que utiliza a ciência não só para o equacionamento de soluções práticas para desafios emergentes, mas também - e principalmente - para a realização de previsões e regulações a cada passo do processo de intervenção na realidade. Embora a "mudança cultural espontânea" também possua caráter intencional, não assegura "a possibilidade de escolher fins alternativos ou exclusivos e de pôlos em prática por meios que assegurem, no mínimo, controle racional do desencadeamento e das principais fases do processo". Só a mudança planejada é capaz de atingir efeitos que podem ser postos em evidência "antes de eles serem produzidos e cuja produção pode ser prevista, regulada e dirigida pelos agentes humanos" (idem, p. 21).

O problema da educação e da ciência aplicada é caracterizado por Fernandes como submetido a "duas ordens contraditórias de condições e de fatores". A primeira diz respeito "à consciência racional dos fins, dos meios e das condições ideais para pô-los em prá- 
tica" (idem, p. 30). Essa consciência existe, usualmente, mesmo nos processos de mudança cultural espontânea. A segunda ordem de fatores refere-se ao "controle racional das diretrizes ultradidáticas e das condições exteriores do processo educacional". $\mathrm{Na}$ ausência desse controle, fica impedida a efetivação de qualquer ideal educacional, pois os educadores são privados de intervir eficazmente nas diversas situações que regulam a vida escolar (idem, p. 33).

É por isso que falham as mudanças desencadeadas espontaneamente. $\mathrm{O}$ elemento racional contido na projeção dos fins acaba desviado de seu curso (idem, p. 34). Diante disso, a proposição de Florestan Fernandes visa garantir que esse curso, estabelecido no planejamento das finalidades almejadas, não seja desvirtuado. Em suma, o autor pretende garantir que haja, na educação, um percurso determinado, seguro e previamente definido. É por intermédio do planejamento que "as experiências do presente são associadas às do passado para prevenir o futuro" (idem, p. 3839). Controle, racionalidade e planificação são palavras decisivas no itinerário imaginado por Fernandes para alterar os rumos da escola brasileira, a qual só contribuirá para "o equilíbrio e o progresso da vida social" quando for abordada segundo "modalidades práticas racionais de tratamento dos problemas educacionais" (idem, p. 44).

A participação da ciência - particularmente das ciências sociais - nesse processo é fundamental. Dada a gravidade da situação brasileira, "é impossível restringir aos 'homens de ação' e aos educadores a responsabilidade pela solução dos problemas educacionais". Por isso, "a cooperação regular dos cientistas sociais se impõe tanto na escolha racional dos fins, quanto na seleção e na exploração racionais dos meios". Por mais que tenham familiaridade com os métodos da pesquisa social, os educadores "dependem dos cientistas sociais" para a tomada de decisões, uma vez que estas exigem avaliações de viabilidade diante das circunstâncias histórico-sociais e, mais do que isso, requerem "a previsão e a verificação do rendimento obtido durante a realização dos planos educacionais" (idem, p. 67).
Florestan Fernandes justifica, assim, uma idéia diferente das concepções de Anísio Teixeira: uma ciência da educação que não se restringe a manter com os educadores uma relação de intercâmbio - ou "comércio permanente", nas palavras do diretor do INEP -, mas que se dispõe a exercer verdadeira tutela sobre os assuntos escolares. A proposta de Fernandes vai muito além daquela visualizada por Teixeira, em que o sociólogo, o antropólogo e outros cientistas permaneceriam estudando os problemas próprios de sua especialidade, mesmo que vinculados às práticas pedagógicas, enquanto os educadores, não sendo cientistas, exerceriam sua "grande arte" de modo tão científico "quanto possível".

A diferença mais marcante entre a exposição do sociólogo da USP e as teses do diretor do INEP, entretanto, é quanto às relações entre a ciência e a filosofia na esfera da educação. No discurso de Fernandes, não há nenhuma menção à presença da filosofia na definição do percurso da mudança cultural e educacional. Esse mesmo traço aparece também em outros escritos veiculados no Simpósio sobre Problemas Educacionais Brasileiros, nos quais se observa a presença de muitos dos conceitos que identificam o raciocínio de Florestan Fernandes com a metáfora percurso determinado.

Nesse enquadramento, destaca-se o trabalho de Raja Nassar, que expressa contundente crítica ao movimento educacional renovador surgido na década de 1920. Embora reconhecendo o mérito dos diagnósticos elaborados pelos escolanovistas pioneiros, Nassar (1968, p. 25-26) assinala que eles não propiciaram o surgimento de "planos e esquemas sólidos e criteriosos através dos quais pudessem ser encontradas as verdadeiras soluções" para os problemas da educação brasileira. Com base nas concepções daquela época, surgiram manifestos de educadores, reformas do ensino e projetos administrativos grandiosos, "grandes planos de reconstrução educacional", mas todo o empenho foi incapaz de transformar a realidade existente em sintonia com os princípios proclamados. A causa do fracasso, segundo esse autor, é que o movimento de renovação carecia de "um plano de 
sedimentação calcado, realmente, num planejamento racional e lógico". Sem "esquema teórico" e "critérios objetivos" de julgamento, as iniciativas de mudança tornavam-se fragmentárias, dissolvendo-se em finalidades obscuras e pouco efetivas.

Nassar faz menção ao Manifesto dos Pioneiros, de 1932, que tentou propor um "plano sistemático" para a educação, em que as finalidades ditassem os meios e, consequientemente, todo o conjunto de fatores atuantes no âmbito escolar. Segundo ele (idem, p. 51-52), "se há algo que se pode negar ao Manifesto, apesar dos seus grandes méritos, é justamente a sistematização de um plano para a educação". Sem uma formulação de conjunto, as idéias ali pleiteadas se tornaram incapazes de subsistir "senão como opiniões pessoais, às vezes procedentes e ditadas pelo bom senso", ou seja, sem nenhuma efetividade concreta, pois a "ação administrativa racional" não se sustenta em meras inclinações pessoais.

Nem mesmo os centros de pesquisas são poupados por Nassar (idem, p. 52). Segundo ele, "pouco ou nada contribuíram e nem contribuirão para o levantamento das deficiências e do rendimento do ensino ou para a proposição de um esquema administrativo que possibilite uma ação efetiva do Estado". A razão desse prognóstico é que os centros viviam "sob o signo da improvisação e do empirismo", sendo os seus "critérios de seleção de problemas e investigação [...] arbitrários e de caráter meramente pessoal". Ali, onde a "característica principal deveria ser a da racionalidade", Nassar vê a ausência de qualquer "representação teórica da realidade educacional" (idem, p. 57).

Autores como Fernandes e Nassar - que não representam a totalidade do simpósio, certamente - expressam um discurso que pleiteia a adoção de estratégias capazes de determinar previamente o itinerário da educação brasileira. ${ }^{9}$ Cada qual a sua maneira e

${ }^{9} \mathrm{O}$ conteúdo desta seção foi desenvolvido mais amplamente no capítulo X de Cunha (1998), em que, além dos trabalhos aqui comentados, são analisados também os estudos de Cardoso e Ianni (1968), Mascaro (1967) e Ribeiro (1967). abordando temáticas específicas, suas falas são compostas por expressões que traduzem idéias de racionalidade, racionalização administrativa, planejamento lógico, precisão diagnóstica, estabilidade e continuidade, sempre buscando apoio na ciência. Geralmente, repercutem críticas, mais ou menos explícitas, a uma série de iniciativas do passado que não conseguiram solucionar os problemas educacionais do país, por falta de planejamento - ou, como diria Fernandes, por falta de controle racional dos fatores envolvidos no processo de mudança.

Vistas em conjunto, tais vozes denunciam a falência da metáfora percurso indeterminado e sugerem a adoção da metáfora percurso determinado. Tal abordagem se identifica com a metáfora organismo, pois descreve a sociedade e a educação como estruturas organizadas, organismos vivos cujas partes precisam ser articuladas por determinados condicionantes, instituições racionalmente equipadas com saberes especializados capazes de dirigir o curso de seu desenvolvimento. O oposto da metáfora piquenique, portanto.

\section{Considerações finais}

No início do presente trabalho, vimos que o campo de debates formado em torno dos centros de pesquisa do INEP possibilitou a "superação" - termo de Libânia Xavier - das contribuições dos pioneiros da renovação educacional pela nova geração de cientistas sociais, grupos em que se incluem, respectivamente, Anísio Teixeira e Florestan Fernandes. Refletindo sobre esse tema mediante a análise retórica, entendemos que a palavra superação, naquele contexto, significa a vitória da metáfora percurso determinado sobre a metáfora percurso indeterminado. Em suma, uma significativa comunidade de ouvintes - educadores e pesquisadores da educação - aderiu à idéia de que o futuro da educação pode e deve ser planejado e controlado para que determinados fins sejam atingidos.

O que se discute na análise do discurso retórico é a sua efetividade perante os ouvintes, o que implica verificar as disposições do auditório que recebe as 
formulações em causa. No caso em estudo, então, cabe buscar as razões pelas quais se tornou plausível ao campo educacional acatar as teses de planejamento, que expressam uma determinada concepção de racionalidade, e rejeitar a noção de incerteza e arte, a qual expressa outro tipo de racionalidade. Essa discussão será desenvolvida, com mais vagar, em outro momento, mas é possível deixar aqui alguns indicativos do que julgamos importante analisar.

a) Entendemos que o debate travado em torno dos centros de pesquisas não diz respeito à contraposição entre ciência e arte, uma vez que, na concepção deweyana, esses dois elementos não se opõem. Dewey vê o caráter de incerteza, que é marcante na atividade artística, presente também na teoria científica mais avançada de sua época, a física quântica. Anísio Teixeira assimila essa concepção ao abordar a educação como arte.

b) No Brasil dos anos de 1950, o que parece estar em jogo são duas concepções de ciência. No vocabulário da análise retórica, podemos dizer que estão em conflito dois discursos que predicam diferentemente a educação por meio da mesma metáfora - ciência -, a qual assume duas conotações diferentes. No primeiro discurso, a referida metáfora traduz noções de incerteza e probabilidade, aproximando-se do conceito de arte. No outro, ciência significa certeza e previsibilidade, identificando-se com tecnologia - melhor dizendo, com uma certa noção de tecnologia, na qual os resultados aplicáveis da ciência, vistos como independentes do processo que os gera, assumem feições deterministas.

c) Essas duas acepções merecem ser mais bem investigadas, no intuito de localizar sua origem e compreender o seu desenvolvimento na história do pensamento ocidental e, particularmente, no Brasil. A primeira acepção da palavra ciência, que se encontra razoavelmente delineada no presente estudo, abre margem para uma reflexão, em maior profundidade, do conceito de arte no pensamento deweyano, bem como das demais metáforas a que eventualmente se vincula. A segunda acepção requer análise ainda mais aprimorada, uma vez que o presente estudo apontou apenas uma parcela de sua manifestação, detectada no pensamento de Florestan Fernandes, em um momento específico de suas formulações.

Acreditamos ser este o itinerário para compreender os fatores envolvidos na "superação" da metáfora percurso indeterminado: tomar a história da idéia de ciência no Brasil, a qual, em sintonia com certa tradição de pensamento, dispôs os ouvintes da década de 1950 a aceitarem uma determinada metáfora, e não outra, para predicar a educação escolar.

MARCUS VINICIUS DA CUNHA, doutor em educação pela Universidade de São Paulo, é professor associado da Faculdade de Filosofia, Ciências e Letras de Ribeirão Preto, da mesma Universidade, no Departamento de Psicologia e Educação. Com bolsa do CNPq, pesquisa o movimento educacional renovador brasileiro dos anos de 1930-1960, especialmente a influência de John Dewey. Publicações recentes: John Dewey, a utopia democrática (DP\&A, 2001) e John Dewey e o pensamento educacional brasileiro (Revista Brasileira de Educação, 2001).E-mail: mvcunha@yahoo.com

\section{Referências bibliográficas}

ARISTÓTELES, (2000). Retórica das paixões. São Paulo: Martins Fontes.

BRANDÃO, Zaia, MENDONÇA, Ana W. P. C. (orgs.), (1997). Uma tradição esquecida: por que não lemos Anísio Teixeira? Rio de Janeiro: Ravil.

CARDOSO, Fernando H., IANNI, Octávio, (1968). As exigências educacionais do processo de industrialização. Estudos $e$ Documentos, São Paulo: Faculdade de Educação da USP, v. 6, p. 197-235.

CUNHA, Marcus V., (1991). A educação no período Kubitschek: os centros de pesquisas do INEP. Revista Brasileira de Estudos Pedagógicos, v. 72, n 171, p. 175-195. , (1998). O discurso educacional renovador no Bra- 
sil (1930-1960): um estudo sobre as relações entre escola e família. Tese de livre-docência. Faculdade de Ciências e Letras de Araraquara, Universidade Estadual Paulista.

(2001). John Dewey e o pensamento educacional brasileiro: a centralidade da noção de movimento. Revista Brasileira de Educação, $\mathrm{n}^{\circ}$ 17, p. 86-99.

DEWEY, John, (1952). La busca de la certeza: un estudio de la relación entre el conocimiento y la acción. México: Fondo de Cultura Económica.

, (1958). Philosophy of education: problems of men.

Ames: Littlefield, Adams \& Co.

, (1959). Reconstrução em filosofia. $2^{\mathrm{a}}$ ed. São Paulo:

Nacional.

FERNANDES, Florestan, (1966). Ensaios de Sociologia Geral e Aplicada. São Paulo: Pioneira.

FERNANDES, Florestan, (1967). A ciência aplicada e a educação como fatores de mudança cultural provocada. Estudos e Documentos, São Paulo: Faculdade de Educação da USP, v. 5, p. 9-74.

FERREIRA, M. S., (2001). O Centro Regional de Pesquisas Educacionais de São Paulo (1956/1961). Dissertação de mestrado. Faculdade de Educação da Universidade de São Paulo.

HEISENBERG, Werner, (1999). Física e filosofia. $4^{\text {a }}$ ed. Brasília: Editora Universidade de Brasília.

MASCARO, Carlos C., (1967). O custeio da educação e a utilização de recursos para as reformas educacionais. Estudos $e$ Documentos, São Paulo: Faculdade de Educação da USP, v. 5, p. 171-193.
MAZZOTTI, Tarso B., (2002). A metáfora percurso no debate sobre políticas educacionais no Brasil contemporâneo. In: VALE, José M. F. et al., (orgs.) Escola pública e sociedade. São Paulo: Saraiva.

MAZZOTTI, Tarso B., OLIVEIRA, Renato J., (2000). Ciência(s) da educação. Rio de Janeiro: DP\&A.

NASSAR, Raja, (1968). Rendimento e deficiências do ensino secundário brasileiro. Estudos e Documentos, v. 6, p. 25-78.

RIBEIRO, J. Querino, (1967). O problema da administração na formação e no desenvolvimento do sistema escolar brasileiro. Estudos e Documentos, São Paulo: Faculdade de Educação da USP, v. 5, p. 137-170.

TEIXEIRA, Anísio, (1952). Discurso de posse do professor Anísio Teixeira no Instituto Nacional de Estudos Pedagógicos. Revista Brasileira de Estudos Pedagógicos, v. 17, n. 46, p. 69-79.

, (1957). Ciência e arte de educar. Educação e Ciências Sociais, v. 2, nº 5, p. 5-22.

VIDAL, Diana G., (org.). (2000). Na batalha da educação: correspondência entre Anísio Teixeira e Fernando de Azevedo (1929-1971). Bragança Paulista: EDUSF.

XAVIER, Libânia N., (1999). O Brasil como laboratório: educação e ciências sociais no projeto do Centro Brasileiro de Pesquisas Educacionais. Bragança Paulista: EDUSF.

Recebido em abril de 2003 Aprovado em outubro de 2003 